\title{
Plastic surgery: A tale of two specialties
}

\author{
William B Riley Jr MD
}

\author{
"It was the best of times; it was \\ the worst of times." \\ Charles Dickens, $A$ Tale of Two Cities, 1859
}

$S^{\circ}$ o it is with plastic surgery today. It is the best of times; it is the worst of times. My thesis is simple. We have not embraced subspecialization. As a result, plastic surgery is now two specialties: cosmetic plastic surgery and reconstructive plastic surgery. We are viable but dysfunctional.

To avoid the pitfalls of tunnel vision and narrow perspective, let us take a 'big picture' look at ourselves.

\section{GLOBAL TRENDS}

In 1970, Alvin Tofler (1) wrote about change as the process whereby the future invades our lives. He coined the term 'future shock', which is the shattering stress and disorientation induced in individuals and organizations subjected to too much change in too short a time.

Future shock is here. We have too much information and too many choices.

What has happened in the past 30 years? A greeting card that plays "Happy Birthday" contains more processing power than existed in the world before 1950. A home video camera contains more processing power than the old IBM 360 that gave birth to the mainframe computer age. A Sega GameBoy has a higher performance processor than the original 1976 Cray Supercomputer that was accessible only to the most elite physicists. Computer power is now 8000 times cheaper than it was 30 years ago. If we had had similar progress in automotive technology, a Mercedes Benz would cost about $\$ 7.00$. It would travel at the speed of sound and run about 600 miles on a thimble of gas. More information has been produced in the past 30 years than during the preceding

Presented as the Royal College of Physicians and Surgeons of Canada Speaker at the 53rd Annual Meeting of the Canadian Society of Plastic Surgeons in Montreal, Quebec, June 25, 1999

Correspondence and reprints: Dr William B Riley Jr, 4665 Sweetwater Boulevard, Suite 110, Sugar Land, Texas 77479, USA. Telephone 281-980-0999, fax 281-980-0444, e-mail

drriley@signaturesurgery.com
5,000 years. The information supply doubles every five years. And finally, during the 1980 s, $46 \%$ of the companies in the Fortune 500 disappeared.

\section{WHO ARE WE?}

The social scientists have divided people into generations with rather distinctive characteristics that facilitate understanding and management of societal changes. The GIs (born between 1901 and 1924) are civic minded and builders. The 'silents' (born between 1925 and 1942) are adaptive and work behind the scenes. The 'boomers' (born between 1943 and 1960) are idealists and love to preach. Generation X (born between 1961 and 1981) comprises individuals ('Xers') who are reactive and cynical. Because the Xers are the newest generation of practising plastic surgeons and residents, let us take a closer look at those who represent the future of the specialty.

Xers blame the boomers for many of their problems, whereas boomers see Xers as lazy and unfocused, and love to preach. There are 44 million Xers and 77 million boomers. The Xers are children of upheaval $-40 \%$ are from broken homes. They grew up in an antichildren era and became independent at a young age. They are products of television sexuality and violence, and have a television remote control or channel 'surfing' attention span. They are cynical and exhibit less loyalty and commitment to their job or profession. They have trouble with authority figures and frequently question the boss. They grew up with television and computers. They are technoliterate and communicate in 'sound bytes'. They seek instant gratification - they want it now and want it fast. They are unsure about the future. They stay home longer, and marry and start families much later. They have received mixed messages on women's roles. They crave attention.

What are the positive aspects of generation X? These individuals grew up in adversity and are equipped to handle it. They are extremely pragmatic and want to get things done. They show signs of a return to 'better' values. They are entrepreneurs.

How does one deal with Xers? Do not preach to them 
because they are cynical. Assign short term, intensive projects with few meetings because they have short attention spans.

Keep them informed and aware about the future because they are uncertain about the future. Set goals and stay hands off because they distrust authority (personal communication).

\section{TRENDS IN MEDICINE}

We live in an age when molecular biology offers the promise of eliminating much human suffering through genetic engineering. We are told that the technology exists to extend the human life span to about 400 years. On the other hand, the health care delivery system began the century as a cottage industry and will end the century as a cottage industry. Enter managed care and centralized bureaucracies with corresponding loss of physician autonomy and declining reimbursement. The health care environment is now characterized by mergers and acquisitions among institutions and organizations and a significant professional work force oversupply (2). The public demands what has been described as a 'crescendo of quality'. Both certifying and accrediting organizations are focusing on competence, which has been defined as knowing what you know, knowing what you do not know and knowing when it makes a difference. Competence is a continuum that begins in medical school, expands in residency and continues throughout practice life. Academicians are considering applying the Dreyfus model of skill acquisition to health care professionals. This model describes progressive stages of skill acquisition, such as novice (medical student), advanced beginner (resident), competent (early practice), proficient (continuing medical education), expert and master. Both expert and master have exceptional skills and outcomes, but an expert dislikes surprises, while a master welcomes surprises. The vast majority of plastic surgeons with a mature practice fall into the proficient category in the Dreyfus mode.

The issue of physician competence becomes complex when certification is considered. Clearly, the public equates board certification with competence and recertification with continuing competence. There are precious few data to confirm such assumptions. What is clear is that accrediting and certification organizations such as the Accreditation Council for Graduate Medical Education (ACGME) and The American Board of Medical Specialties (ABMS) place significant emphasis on the assessment of competence during the coming decade. Clinical outcomes will be the indicators of quality, and clinical decision making will become much more evidence-based.

Another notable trend in medicine is the resolution of many interspecialty turf battles in recent years. Although plastic surgery as a specialty continues to be encroached by other disciplines into its core curriculum, particularly cosmetic surgery, it is my observation that specialties that attempt to protect turf inevitably lose those battles. Once again, outcomes, not hype or tradition, will determine future success. Practice patterns are quite variable and continually changing. Fewer physicians subscribe to vertical practice patterns, wherein they practice within the defined scope of the specialty in which they were trained and certified. Indeed, it is becoming more common for physicians to engage in horizontal practice patterns in which they extend their practices beyond the scope of their training and certifications for socioeconomic reasons. Organized medicine and regulatory agencies alike show no signs of attempting to limit or reverse such trends.

\section{TRENDS IN PLASTIC SURGERY}

Where does plastic surgery fit into this sweeping panorama of global change? We readily accept technical innovations and, indeed, all too often incorporate so called 'new advances' into the operating room and our practices before they have withstood longer term scientific scrutiny. But what about the educational and organizational aspects of our specialty'?

Consider the following observations. Attendance at reconstructive symposia has decreased, while attendance at cosmetic symposia has increased. Attendance at the American Association of Plastic Surgeons' annual meeting has decreased, while attendance at the American Society for Aesthetic Plastic Surgery annual meeting has increased. Most plastic surgeons perform little or no surgery in the following categories: cleft lip and palate, pressure sores, maxillofacial trauma, burns, free flaps, congenital and genitourinary. The ACGME program requirements for plastic surgery, however, require significant training in all the above areas. Increasing numbers of generation Xers are entering residency programs with primary interest in cosmetic surgery and relatively little interest in reconstructive surgery. They tolerate two or three years of training emphasizing reconstructive surgery to get their 'ticket' to practice cosmetic surgery. Increasing numbers of residents feel that their training is inadequate in length and scope, particularly in cosmetic surgery. The annual number of graduates in the United States entering the plastic surgery work force remains stable at approximately 200 , but there are approximately 60,000 physicians practising some aspect of cosmetic surgery. Surveys continue to show that plastic surgeons feel more competition from fellow plastic surgeons than from other specialties. There are over 100 self-designated or non-ABMS boards, at least 12 of which deal with cosmetic surgery. Plastic surgery has even witnessed the formation of a self-designated board of its own, the American Board of Aesthetic Plastic Surgery, the future of which is uncertain at this time. Five years ago, members of the American Society for Plastic \& Reconstructive Surgeons narrowly rejected a proposal to change the name of the society to the American Society of Plastic Surgeons, a name that promotes unity, communicates more clearly to the public the nature of the specialty and is more in harmony with the names of other major plastic surgery organizations. For the past several years, the American Society for Aesthetic Plastic Surgery has shown little interest in obtaining a seat in the American Medical Association House of Delegates. That interest was heightened, however, when the 
American Academy of Cosmetic Surgery recently won a seat. The Residency Review Committee for Plastic Surgery only recently began to use ACGME professional staff for training program site visits - the last of the 24 ABMS specialties to do so. The reasoning had always been that no one can assess the quality of a plastic surgery training program better than a plastic surgeon. The change in policy was prompted by recognizing that professional site visitors deliver a higher quality product than busy plastic surgeons. The American Board of Plastic Surgery (ABPS) last year became the last ABMS specialty board to hire an executive director and was the next to last specialty board to approve a plan for recertification. Furthermore, ABPS has, until recently, been on record as opposing subcertification because it was viewed as a catalyst for fragmentation.

\section{CONCLUSIONS}

What can be concluded from the above observations regarding the behaviour of plastic surgery as a specialty? There appears to be an increasing disconnection between what we teach and what we do. We have had an attitude of 'if it ain't broke, don't fix it'. Avoiding recognition of subspecialization has resulted in the very thing that we have feared the most - fragmentation, ie, into cosmetic and reconstructive surgery. The next step in this process of self-destruction is isolation. Fragmentation is reversible. Isolation is not. Isolation is terminal.

\section{FUTURE: WHAT DO WE DO NOW?}

We must recognize that plastic surgery is now two specialties: reconstructive plastic surgery and cosmetic plastic surgery. We must recognize that change is normal. We must recognize that change within the specialty must be understood within the broader context of world, country and profession. We must recognize that change can frequently be guided or directed, but never stopped. We must be willing to think "out of the box" and consider a paradigm shift in the format of our training programs to preserve the scope of plastic surgery, yet provide options and flexibility in specialty and subspecialty experience. We must be willing to compromise on nonessential issues. We must be willing to accept risk. We must be willing to cultivate allies within competing specialties. We must promote our diversity, our creativity, our outcomes, our compassion and our volunteerism.

The world is full of faces, young and old, that look to us to improve the quality of their lives in varied ways. No one has done it better. If we are willing to look at ourselves and make some changes, no one will do it better in the next century. And I end this 'tale of two specialties' by thanking you for the privilege of sharing my thoughts and wishing you and your society the very best of times.

\section{REFERENCES}

1. Tofler A. Future Shock. New York: Random House, 1970.

2. Coddington D. Capitalizing Medical Groups. New York: McGraw-Hill, 1998.
CLASSIFIED ADVERTISING

\section{COSMETIC PLASTIC PRACTICE WEB SITE SPECIALISTS}

Affordable web sites by web developer to: the CSPS, CSAPS, ASLMS, ISBI, ASCEQ, CAFPRS, CLASS, IPRAS,

Operation Rainbow \& many private cosmeticplastic practices

\section{GRAY COMMUNICATIONS INC Toronto}

Telephone: 416-340-1518

Fax: 416-341-0060

E-mail: admin@graycommunications.ca

Web site: http://www.graycommunications.ca
The Journal is available online! Bookmark

The Canadian Journal of Plastic Surgery www.pulsus.com/PLASTICS/home.htm

\section{CLASSIFIED ADVERTISING}

\section{INCREASE YOUR REVENUE}

\author{
Pre-owned LPG Endermologie cellulite \\ reduction systems, ESC Eplight hair removal \\ and laser systems.
}

Also Synergy equipment and tables, new \& used. Many systems at $30-50 \%$ less than new.

Financing/leasing available.

Call CMC at (800) 854-3504 